\title{
ESPACIOS MARINOS PROTEGIDOS EN EL ÁREA DEL ESTRECHO DE GIBRALTAR: INCIDENCIA DEL BREXIT
}

\section{MARINE PROTECTED AREAS IN THE STRAIT OF GIBRALTAR ZONE: THE INCIDENCE OF BREXIT}

\author{
Jesús Verdú BAEZA \\ Profesor Titular de Derecho Internacional Público y Relaciones Internacionales \\ Universidad de Cádiz \\ jesus.verdu@uca.es
}

Fecha de recepción: 4 de octubre de 2019 / Fecha de aceptación: 2 de diciembre de 2019

\section{RESUMEN}

El estrecho de Gibraltar es un espacio geográfico singular. Vía de comunicación entre el Mediterráneo y el océano Atlántico, es el lugar de encuentro de dos continentes. Sus especiales características determinan la existencia de un área marina extraordinariamente valiosa con una rica diversidad, además de ser una ruta privilegiada de migración de aves y especies marinas.

Sobre esa área, de enorme importancia geoestratégica, se proyecta un conjunto de controversias políticas y jurídicas de los tres Estados presentes en la zona, España, Marruecos y el Reino Unido a través de Gibraltar. Como consecuencia, no existen acuerdos de delimitación marítima ni esquemas de cooperación transfronteriza. La protección medioambiental depende fundamentalmente de los ordenamientos internos de los Estados, no existiendo ninguna área marina protegida de acuerdo con alguna de las posibilidades existentes en la normativa medioambiental internacional. No obstante, si existen varias zonas incluidas en la red europea Natura 2000 bajo responsabilidad española y británica que presentan ciertas discontinuidades y un llamativo solapamiento. 
Si el Reino Unido decidiera salir de la Unión Europea, la salida tendría unas consecuencias directas sobre la protección ambiental y el esquema de zonas marinas protegidas, generando un escenario de incertidumbre.

\section{RESUM}

L'estret de Gibraltar es un espai geogràfic singular. Via de comunicació entre el Mediterrani i l'oceà Atlàntic, és un lloc de trobada de dos continents. Les seves especials característiques determinen l'existència d'un àrea marina extraordinàriament valuosa amb una rica diversitat, a més de ser una ruta privilegiada de migració d'aus i espècies marines.

Sobre aquesta àrea, de gran importància geoestratègica, es projecta un conjunt de controvèrsies polítiques i jurídiques dels tres Estats presents a la zona, Espanya, el Marroc i el Regne Unit a través de Gibraltar. Com a conseqüència, no existeixen acords de delimitació marítima ni esquemes de cooperació transfronterera. La protecció mediambiental depèn fonamentalment dels ordenaments interns dels Estats, no existint cap àrea marina protegida d'acord amb alguna de les possibilitats existents a la normativa mediambiental internacional. No obstant, si existeixen vàries zones incloses a la xarxa europea Natura 2000 sota responsabilitat espanyola i britànica que presenten certes discontinuïtats i un cridaner solapament.

Si el Regne Unit decidís sortir de la Unió Europea, la sortida tindria unes conseqüències directes sobre la protecció ambiental i l'esquema de zones marines protegides, generant un escenari d'incertesa.

\section{ABSTRACT}

The Strait of Gibraltar is a unique geographical zone. Communication route between the Mediterranean and the Atlantic Ocean, it is the meeting place of two continents. Its special characteristics determine the existence of an extraordinarily valuable marine area with a rich diversity, in addition to being a privileged route of migration of birds and marine species.

Over this territory, of paramount geostrategic importance, an array of political and legal controversies of the three States present in the area, Spain, Morocco and the United Kingdom (Gibraltar) is projected. Consequently, there are no maritime 
delimitation agreements or cross-border cooperation schemes. Environmental protection depends fundamentally on the internal regulations of the States. There are not any MPAs in the zone in accordance with any of the possibilities existing in international environmental regulations. However, there are several areas included in the European Natura 2000 network under Spanish and British responsibility presenting certain discontinuities and a striking overlap.

If the United Kingdom decides to leave the European Union, the exit would have direct consequences on the environmental protection and the scheme of protected areas generating a scenario of uncertainty.

Palabras clave: Estrecho de Gibraltar - áreas marinas protegidas - Brexit.

Paraules clau: Estret de Gibraltar - àrees marines protegides - Brexit.

Key words: Strait of Gibraltar - Maritime protected areas - Brexit.

SUMARIO $1 \mathrm{El}$ estrecho de Gibraltar: un espacio marítimo singular 2 Riesgos y amenazas presentes en el estrecho 3. Controversias jurídicas en la zona del estrecho: falta de delimitación de los espacios marítimos 4. Espacios marinos protegidos por instrumentos internacionales en el estrecho 5. Solapamiento de áreas marinas protegidas en la bahía de Algeciras/Gibraltar. 6. El Brexit como amenaza a la protección ambiental 7. Conclusiones 8. Bibliografía

\section{EL ESTRECHO DE GIBRALTAR: UN ESPACIO MARÍTIMO SINGULAR}

Sin duda, el estrecho de Gibraltar es uno de los espacios marinos más singulares del planeta. Zona con una importante carga mitológica al ser durante cientos de años el límite del mundo conocido, como cierre del mar Mediterráneo, y base de las legendarias columnas de Hércules. Por un lado, como vamos a mencionar, aunque sea sucintamente, en este trabajo, sus características geofísicas y naturales, en cuanto que punto de intercambio de masas de agua del Mediterráneo y del Atlántico con diferente temperatura y salinidad y su ubicación como elemento de separación de dos continentes, África y Europa, tienen como consecuencia constituir uno de los ecosistemas marinos más valiosos del globo, 
con una rica y alta biodiversidad, además de ser también ruta principal de importantes flujos migratorios, tanto de aves como de especies marinas.

Por otro lado, como única comunicación natural entre el Atlántico y el Mediterráneo (y hasta la construcción del canal de Suez y su inauguración en 1869, la sola vía de entrada y salida del Mediterráneo) es un espacio geoestratégico de primer orden, que ha condicionado la presencia variable de diversas potencias con intereses en sus orillas ${ }^{1}$. Finalmente, y como resultado de un convulso y complejo proceso histórico y político en el área geográfica cercana $^{2}$, con especiales circunstancias históricas cuyas raíces se proyectan varios siglos en el pasado, a ambas orillas del estrecho se proyectan una serie de controversias jurídicas y políticas sobre diversos territorios y los espacios marinos adyacentes que determinan la inexistencia de acuerdos de delimitación entre los tres Estados presentes en la zona (España, Marruecos y el Reino Unido), y, en consecuencia, se genera una permanente inestabilidad que cristaliza periódicamente en crisis políticas de desigual magnitud, tanto en la costa norte como en la sur, con un alto potencial de desestabilización.

La compleja historia geológica del estrecho de Gibraltar ha promovido que esta región destaque por sus niveles de biodiversidad en la, ya de por sí rica, cuenca del Mediterráneo. Como indicamos anteriormente, el área del estrecho de Gibraltar incluyendo la Bahía de Algeciras/Gibraltar reúne una gran riqueza en ecosistemas y biodiversidad propiciada por su situación geográfica, lugar de encuentro, por un lado, del mar Mediterráneo y el océano Atlántico y por otro, de los continentes africano y europeo, y define geográficamente un lugar privilegiado que alberga una sorprendente variedad de seres vivos y es testigo de fenómenos biológicos excepcionales, tanto en el medio terrestre como el marino. Todo el área constituye una zona de elevado interés biológico y biogeográfico, al converger tres provincias biogeográficas distintas; la lusitánica, la mauritánica y la mediterránea, lo que confiere a la zona una gran singularidad

\footnotetext{
${ }^{1}$ S. C. Truver, The strait of Gibraltar and the Mediterranean, Sithoff \& Noordhoff, 1980.

2 Joaquín Cestino Pérez, El estrecho, treinta siglos de historia en Gibraltar, Tánger, Tarifa, Ceuta y Algeciras, Editorial Arguval, Málaga, 2004.
} 
${ }^{3}$ conocida desde la antigüedad ${ }^{4}$, y con un gran número de especies naturales muy valiosas, así como una sorprendente cifra de endemismos.

El ámbito marino del estrecho debido a su situación privilegiada es una zona singular y su entorno es uno de los espacios marinos del mundo con mayor valor ecológico, como zona de transición y con una geomorfía muy compleja, existiendo una gran diversidad y presencia de especies tanto de la cuenca del Mediterráneo como del Atlántico, y en la que los investigadores van encontrando nuevas especies con cierta frecuencia ${ }^{5}$.

Debido a las características singulares de la zona, dominada por fuertes corrientes profundas procedentes del Mediterráneo, aguas cargadas de nutrientes orgánicos y más cálidas que las superficiales atlánticas, desde hace algún tiempo se han venido desarrollando estudios científicos de los hábitats desde una perspectiva no sólo geológica sino también eco-sistémica, es decir, desarrollando iniciativas de catalogación de las especies que habitan esos fondos marinos, estableciendo su valor biológico y sus relaciones específicas, su aportación a la diversidad y los riesgos de supervivencia ${ }^{6}$.

\footnotetext{
3 Jesús Cabello Medina, "Parque Natural del Estrecho, un nuevo futuro" en Medio Ambiente, Consejería de Medio Ambiente de la Junta de Andalucía, n 43, primavera, 2003.

${ }^{4}$ Estrabón mantenía una curiosa teoría basada en que la riqueza de la fauna marina en esta zona estaba motivada por el hecho de que los bosques llegaran a la línea de costa: "Los congrios se desarrollan allí enormemente y sobrepasan por su tamaño en mucho a los nuestros, también hay muchos otros peces de la misma especie, muchos atunes que llegan desde el Mar Exterior (Océano Atlántico), llegan a estas costas y son gordos y grasosos. Nútrense de las bellotas de cierta encina que crece en el mar y que produce frutos en verdad muy abundantes, produce tanto fruto que después de la marea alta, así la costa de la parte interior como en la parte exterior de las Columnas (Gibraltar) queda cubierta de las que arroja la pleamar..." Texto citado en el artículo reseñado en la nota anterior.

${ }^{5}$ Entre la abundante bibliografía sobre la fauna marina podemos citar: Gibraltar Ornithological and Natural History Society (GONHS), The Habitats Directive and Gibraltar: Implementation in Gibraltar of Council Directive on the Conservation of Natural Habitats and of Wild Flora and Fauna, Gibraltar, 1994, Anthony Santana, "La conservación de los mamíferos en Gibraltar" en Revista de Estudios Campogibraltareños, Almoraima, v. 15, 1996, pp. 191 - 196, Eric Shaw, "Gibraltar's Sea Grass Meadows" en Gibraltar Nature News, v. 43, Gibraltar, 1992, Eric Shaw "Dolphins in the Bay of Gibraltar" en Revista de Estudios Campogibraltareños Almoraima, v. 13, 1996, pp. 161 - 171, José Carlos García Gómez, "Adiciones a la fauna de opistobranchios del Estrecho de Gibraltar" en Iberus, v. 6, 1987, pp. 197 - 209.

${ }^{6}$ Esteban Pacha Vicente, Propuesta de designación de Zona Marina Especialmente Sensible del Estrecho de Gibraltar y Golfo de Cádiz, Tesis doctoral, Universitat Politècnica de Catalunya, 2004, p. 173, consultada en https://www.tesisenred.net/handle/10803/277379\#page=1 (última consulta el 12 de agosto de 2019).
} 
En los ámbitos marinos de aplicación de normativa ambiental europea en el estrecho de Gibraltar se encuentran especies que determinarán la necesidad de identificar áreas de protección, circunstancia que, a su vez, generará unas controversias específicas como veremos más adelante en este trabajo. En esta zona se encuentran tres especies incluidas en el Anexo II (especies animales o vegetales de interés comunitario para cuya conservación es necesario designar zonas especiales de conservación) de la Directiva 92/43/CEE, del Consejo, de 21 de mayo, relativa a la conservación de los hábitats naturales y de la fauna y flora silvestre: la tortuga boba (Caretta Caretta), el delfín mular (Tursiops Truncatus) y la marsopa (Phocoena Phocoena). Más de veinte especies se encuentran recogidas en el Anexo IV (especies animales o vegetales de interés comunitario que requieren una protección) de la citada directiva entre las que se encuentran cuatro especies de tortugas marinas y varias especies de cetáceos ${ }^{7}$. Las condiciones oceanográficas y meteorológicas del estrecho de Gibraltar favorecen especialmente la presencia de cetáceos como consecuencia del fenómeno de retención de nutrientes que causa el intercambio de masas acuáticas atlánticas y mediterráneas. Hay especies residentes habitualmente en las aguas del sstrecho, como el delfín común, mientras que otras son migratorias, como el cachalote o la orca.

Durante varios siglos, la pesca de cetáceos fue una actividad económica relativamente importante en la zona, como testimonian los restos de diversas factorías a ambas orillas del estrecho de Gibraltar $^{8}$, pesca que, al parecer, se realizaba ya desde las diferentes ciudades factoría romanas especializadas en la producción de garum, producto muy apreciado en Roma derivado de la sangre y vísceras del pescado, de gran importancia en su época y cuyos espectaculares vestigios se están estudiando actualmente ${ }^{9}$. Estas ruinas son además un atractivo polo de desarrollo turístico (como la ciudad de Baelo Claudia en Tarifa).

\footnotetext{
7 Entre las ballenas, podemos citar la Balaenoptera Borealis, la Balaenoptera Physalus, la Magaptera Novaeangliae, la Eubalaeana glacialis y la Physeter Catodon y entre los delfines, el Delphinus Delphis y el Stenella Coeruleoalba. M. Fernández Casado, "Aproximación al estudio de las poblaciones de las diferentes especies de cetáceos en el estrecho de Gibraltar: resultados preliminares" en Revista de Estudios Campogibraltareños, Almoraima, n² 23, 2000, pp. 209 218.

${ }^{8}$ A. Aguilar y A. Borrell, "Open-boat whaling on the Straits of Gibraltar ground and adjacent waters". Marine Mammal Science, 2007, vol. 23, no 2, p. 322-342.

${ }^{9}$ Dario Bernal-Casasola, "Whale Hunting in the Strait of Gibraltar during the Roman Period", SAA Archaeological Record, 2018.
} 
Igualmente, en relación con el anexo $\mathrm{V}$ de la directiva Hábitats (especies de interés comunitario cuya recogida en la naturaleza y cuya explotación puede ser objeto de medidas de gestión) se incluye una especie presente en el litoral del estrecho: el coral rojo (Corallium Rubrum) establecido en zonas específicas de fondos rocosos superiores a cuarenta metros de profundidad y que sufre en la actualidad una fuerte presión por su alto interés económico, fundamentalmente de buques bajo pabellón italiano. Además, existen en los fondos marinos importantes extensiones de praderas de fanerógamas marinas (Cymodea Nodosa), poríferos (esponjas) como la Axinella Estacioi, los cnidarios (medusas) como la Merona Cervera atlántica y la Scleranthelia Microsclera y otras especies de enorme interés como moluscos, crustáceos, equinodermos y briosos que conviven en hábitats caracterizados por comunidades biológicas bien estructuradas y con elevada biodiversidad asentada sobre fondos rocosos heterogéneos ubicados entre los 10 y 50 metros de profundidad. Destacamos la Patella Ferruginea, considerada la lapa de mayor tamaño de las costas europeas y actualmente en peligro de extinción. Por último, las algas rojas calcáreas integrantes de los llamados fondos de mäerl, localizados a partir de los veinte metros de profundidad donde la luz llega con poca intensidad, constituyen enclaves con una muy elevada riqueza biológica ${ }^{10}$. También se han encontrado e identificado comunidades de corales profundos como Lophelia Pertusa, un coral de crecimiento muy lento y de inmenso valor ecológico, así como diversas esponjas, gorgonias y crinoides, o poliquetos. Todo ello le confiere un carácter propio de áreas de rica biodiversidad.

\section{RIESGOS Y AMENZAS PRESENTES EN EL ESTRECHO}

Esta zona tan singular y valiosa en términos ecológicos está sometida a un enorme número de riesgos y amenazas derivadas de una compleja mezcla de factores. Siendo extraordinariamente larga y diversa la lista, haremos una breve mención de algunas de las que tienen mayor entidad.

\footnotetext{
10 Información obtenida en relación con la costa española del estrecho del Plan de Ordenación de los Recursos Naturales del Frente Litoral Algeciras - Tarifa, aprobado por Decreto 308/2002 de la Junta de Andalucía, de 23 de diciembre (BOJA n 18, de 28 de enero de 2003).
} 
El estrecho de Gibraltar es una de las principales rutas marítimas internacionales del mundo, con mayor densidad de tráfico, punto obligado de paso para todos los buques cuyas líneas unen los puertos del Atlántico y Norte de Europa con los del Mediterráneo e incluso los más importantes puertos de las costas de Asia y el Golfo Pérsico, a través del Canal de Suez, además de los buques y ferries que unen el norte de África con Europa a modo de puente marítimo. Además, debemos añadir una importante presencia de buques de recreo en torno a los núcleos turísticos de sus costas y una nada desdeñable presencia de una flota pesquera con base en sus puertos. Finalmente, su ubicación estratégica favorece la presencia habitual de embarcaciones militares de las potencias tanto costeras como de otros Estados con intereses en la zona, pero muy alejados geográficamente ${ }^{11}$.

En lo que respecta al tránsito por el estrecho, a pesar de la inexistencia de acuerdos de delimitación de espacios marítimos, en el marco de la Organización Marítima Internacional, al menos, existe un dispositivo de separación del tráfico, con instalaciones de control, tanto en España como en Marruecos, a fin de coordinar y ordenar el tráfico y prevenir los accidentes ${ }^{12}$.

Atravesando el estrecho de Gibraltar más de ciento diez mil buques anualmente, debemos destacar que el régimen jurídico relativo a la navegación por este estrecho, tal y como está regulado en la Convención de Naciones Unidas sobre Derecho del Mar de 1982 en su Parte III (Estrechos utilizados para la navegación internacional), denominado paso en tránsito, favorece, en principio, la libertad de navegación de los buques, limitando severamente las facultades y posibilidades de control de los Estados ribereños, en particular aquellas de contenido de protección medioambiental, en relación con otras categorías de estrechos y otros espacios marítimos regulados en la Convención ${ }^{13}$.

\footnotetext{
11 Véase el interesante trabajo de Luis Romero Bartomeus, "Los actores que intervienen en la estrategia del Estrecho de Gibraltar", Cuadernos de Gibraltar / Gibraltar Reports, n² 2, 2016 2017, pp. $147-223$.

${ }^{12}$ Miguel Ángel Cepillo Calvin, "El dispositivo de separación del tráfico marítimo en el estrecho de Gibraltar", en José Manuel Sobrino Heredia (dir.), La contribución de la convención de Naciones Unidas sobre derecho del mar a la buena gobernanza de los mares y océanos, Editoriales Scientifica, Nápoles, vol. 2, 2014, pp. 731 - 745.
}

${ }^{13}$ Véase José Antonio Yturriaga Barberán, Straits Used for International navigation: A Spanish Perspective, Nijhoff Dorddrecht, 1991; Ana Gema López Martín, La navegación por los estrechos: geoestrategia y derecho, Dykinson, Madrid, 2008; Victor Luis Gutiérrez Castillo, 
Además, la fuerte presión antrópica mediante importantes desarrollos urbanos, portuarios e industriales, en el norte y en el sur, constituyen también una importante amenaza para la zona ${ }^{14}$, tanto por los vertidos, descargas y emisiones como el incremento de escalas en los puertos del estrecho ${ }^{15}$. Además, el establecimiento de nuevas rutas de navegación que, como en el caso de las recientes instalaciones portuarias de Tanger-Med que han modificado sustancialmente la costa marroquí del estrecho, multiplican los factores de riesgo en las escalas de los buques ${ }^{16}$. A título de ejemplo, la conexión de Tanger Med hacia España, fundamentalmente hacia el puerto de Algeciras, incide en una zona altamente sensible de reproducción de cetáceos ${ }^{17}$.

Adicionalmente, un importante factor de riesgo está en la importante presencia de buques y submarinos militares, con un régimen jurídico específico como buques de Estado, que navegan por el estrecho como un espacio geoestratégico, algunos de ellos con propulsión nuclear (o portando armamento nuclear), siendo que algunos de los cuales han sufrido ya alguna avería o, incluso, colisiones en la zona.

Por otra parte, el insuficiente control de los vertidos de agua de lastre de los buques que fondean en esta zona tan sensible está causando en la actualidad una catástrofe ecológica sin precedentes. En 2015, se detectó en el estrecho de Gibraltar un alga invasora procedente de Asia, probablemente introducida en el

\footnotetext{
"Estudio del régimen jurídico del Estrecho de Gibraltar: conflictos de soberanía, espacios marinos y navegación", en Alejandro del Valle Gálvez, Rachid El Houdaigui y Miguel Acosta Sánchez, Las dimensiones internacionales del Estrecho de Gibraltar, Dykinson, Madrid, 2006, Valentín Bou Franch, La navegación por el mar territorial, incluido los estrechos internacionales y las aguas archipelágicas, en tiempo de paz, Iberediciones, Madrid, 1994.

${ }^{14}$ Rabia M'Rabet Temsamani,, El Estrecho de Gibraltar: la protección internacional y nacional de su medio ambiente marino, editorial Dykinson, Madrid, 2018.

${ }^{15}$ Los principales puertos del estrecho de Gibraltar son el de Algeciras (con instalaciones en todo el arco de la Bahía de Algeciras y dependiente de él, el puerto de Tarifa), Gibraltar, Ceuta y Tánger Med. En cuanto a número de personas, contenedores y bunkering o suministro de buques, la actividad de estos puertos es una de las más importantes de todo el Mediterráneo.

${ }^{16}$ No obstante, antes las dificultades jurídicas de control del paso en tránsito por el estrecho de acuerdo con el derecho del mar, el control por los Estados de puerto abre ciertas posibilidades de control, inspección y sanción. Sobre el control por el Estado de puerto, véase Teresa Fajardo del Castillo, "Control por el Estado de puerto: cambio de rumbo en el derecho internacional", en José Manuel Sobrino Heredia, Mares y océanos en un mundo en cambio: tendencias jurídicas, actores y factores, Tirant lo Blanch, Valencia, 2007, pp. $401-426$.

${ }^{17} \mathrm{M}$. Pateau, "Le complexe portuaire "Tanger Med", une stratégie économique aux dépens d'une gestion durable de risques naturelles", Geographies, Bulletin de l'Association de Géographes Français, vol. 91, n 3, 2014, pp. $389-340$.
} 
agua de lastre de un buque, denominada Rugulopteryx okamura, que desde entonces ha mostrado un crecimiento y dispersión que ha sorprendido a la comunidad científica, al tener una capacidad competitiva desbordante desplazando casi totalmente la biota local. En 2019 gran parte de los fondos del estrecho de Gibraltar, por sus dos frentes litorales, están colonizados por la especie invasora con un impacto severo sobre las especies autóctonas, además de sobre la actividad pesquera y turística en la zona ${ }^{18}$.

\section{CONTROVERSIAS JURÍDICAS EN LA ZONA DEL ESTRECHO: FALTA DE DELIMITACIÓN DE LOS ESPACIOS MARÍTIMOS}

Por supuesto, no podemos analizar con profundidad la extraordinaria complejidad jurídica y política de las diversas controversias territoriales existentes en la zona, ya que desbordaría el propósito de este trabajo ${ }^{19}$, pero debemos subrayar que, como consecuencia, no existe ninguna delimitación marítima válidamente acordada mediante tratado internacional en el área del estrecho de Gibraltar. Por lo tanto, cada uno de los Estados presentes en el estrecho, España, Marruecos y Reino Unido (a través de Gibraltar) dispone de delimitaciones marítimas unilaterales no coincidentes con las de los Estados vecinos o situados en frente. En definitiva, existen tres delimitaciones marítimas diferentes en el estrecho de Gibraltar y ninguna de ellas es aceptada por el resto de los Estados presentes en la zona.

En relación con las aguas en torno al territorio de Gibraltar, es bien conocida la diferencia de tesis jurídicas entre las partes implicadas en la controversia que conducen a posicionamientos y conclusiones enfrentadas ${ }^{20}$. Mientras que España mantiene todavía en la actualidad la tesis conocida como de costa seca, esto es, la inexistencia de aguas bajo jurisdicción gibraltareña o soberanía británica, tal y como se diseñó en el período franquista, alejándose de la práctica

\footnotetext{
${ }^{18}$ Martín Serrano, "Un alga asiática invade el estrecho de Gibraltar y pone en grave peligro su ecosistema", Reach/Alcance, n 16, agosto de 2019, p. 8.

${ }^{19}$ Para profundizar en ellas, es altamente aconsejable la obra de Máximo Cajal, Ceuta, Melilla, Olivenza y Gibraltar, ¿Dónde acaba España?, editorial Siglo XXI, Madrid, 2003.

20 Alejandro del Valle Gálvez, "Maritime Zones around Gibraltar", Spanish Yearbook of International Law, $\mathrm{n}^{\circ}$ 21, 2017, pp. 311 - 326. Araceli Mangas Martín, "Gibraltar: Adjacent Waters to the territory Yielded by Spain" en Pablo Antonio Fernández Sánchez, New Approaches to the Law of the Sea, Nova Science Publishers, 2017, pp. $31-45$.
} 
española anterior ${ }^{21}$, el Reino Unido, y, por supuesto, Gibraltar, mantiene que el territorio dispone de derechos sobre las aguas adyacentes a la roca en virtud tanto de los términos de cesión del territorio de Gibraltar en el tratado de Utrecht, como, fundamentalmente, de acuerdo con los principios y reglas del Derecho Internacional del mar actualmente vigentes ${ }^{22}$.

En relación con la orilla sur del estrecho, las controversias surgen en torno a las ciudades, islas y peñones españoles en el norte de África que no son reconocidas por Marruecos, y, por lo tanto, para este Estado, no generan espacios marinos bajo soberanía y jurisdicción española. De hecho, Marruecos en su normativa interna relativa al establecimiento de Líneas de Base Recta a partir de las cuales delimita su mar territorial ${ }^{23}$, se apoya en accidentes geográficos situados en territorios bajo soberanía española ${ }^{24}$. El Reino de Marruecos al ratificar la Convención de Naciones Unidas sobre el Derecho del Mar en 2007 efectuó una Declaración en la que aclaraba que tal ratificación no suponía reconocimiento alguno de soberanía española de los territorios españoles en la costa mediterránea de Marruecos, esto es, Ceuta, Melilla, Peñones de Vélez de la Gomera y Alhucemas y las Islas Chafarinas ${ }^{25}$.

La existencia de estas controversias jurídicas tanto en el norte como en el sur que impiden la celebración de acuerdos de delimitación de los espacios

\footnotetext{
${ }^{21}$ En mis trabajos Jesús Verdú Baeza, "La controversia sobre las aguas de Gibraltar: el mito de la costa seca", Revista Española de Derecho Internacional, vol. 66, $\mathrm{n}^{\circ} 1$, 2014, pp. $81-123$ y "Las aguas de Gibraltar, el tratado de Utrecht y el Derecho Internacional del Mar", Cuadernos de Gibraltar/Gibraltar Reports, $n^{\circ}$ 1, 2015, pp. 97 - 132 he mantenido una posición crítica en relación con la tesis oficial española al considerarla alejada de la práctica española, contraria a los criterios de negociación del Tratado de Utrecht y contradictoria con los principios y reglas del Derecho Internacional del mar, tal y como están recogidos en la Convención de Naciones Unidas sobre Derecho del Mar.

Con una posición contraria, véase Pablo Antonio Fernández Sánchez, "La controversia sobre la titularidad jurídico-internacional de los espacios jurídicos adyacentes a Gibraltar, Revista Española de Derecho Internacional, vol. 67, $\mathrm{n}^{\circ} 2$ 2, 2015, pp. $13-47$.

22 Puede consultarse esa perspectiva en la obra de Jamie Trinidad, "The disputed waters around Gibraltar", The Bristish Yearbook of International Law, volumen 86, Issue 1, 2016, pp. 101 - 154. ${ }^{23}$ Decreto $n^{\circ} 2-75-311$ de 21 de julio de 1975, publicado en el Boletín Oficial $n^{\circ} 3276$ de 13 de agosto de 1975 ,

${ }^{24}$ Sobre ello, Víctor Luis Gutiérrez Castillo, "La delimitación de aguas marinas españolas en el Estrecho de Gibraltar", Instituto Español de Estudios Estratégicos, Documento de Opinión 29/2011, abril 2011, pp. $1-12$.

${ }^{25}$ La Declaración marroquí puede verse en Eva María Vázquez Gómez, "Crónica de Derecho del Mar (Enero/Junio 2007)", Revista Electrónica de Estudios Internacionales, 14, 2007, pp. 2-3. En el $B O E$ número 274 de 13 de noviembre de 2009, pp. 95491-95492, puede verse la Comunicación de España de 10 de septiembre de 2008, relativa a la Declaración formulada por Marruecos en el momento de la Ratificación que afirma que España ejerce plena y total soberanía sobre dichos territorios.
} 
marítimos del estrecho provoca recurrentemente ciertos episodios de tensión política entre los Estados ribereños, lo que impide, a su vez, la normalización de la cooperación transfronteriza en el ámbito medioambiental ante la ausencia de mecanismos institucionalizados ${ }^{26}$.

\section{ESPACIOS MARINOS PROTEGIDOS POR INSTRUMENTOS INTERNACIONALES EN EL ESTRECHO}

Encontrándose el estrecho de Gibraltar en el extremo occidental del Mediterráneo, puede considerarse que forma parte de él y, en consecuencia, este espacio estaría incluido dentro del marco jurídico internacional de protección medioambiental específico de esta cuenca marítima ${ }^{27}$.

Básicamente, las normas de referencia de este marco que, al ser de aplicación al Mediterráneo, comprenderían las aguas del estrecho de Gibraltar, serían el Convenio para la protección del medio marino y de la región costera del Mediterráneo o Convenio de Barcelona, el Protocolo sobre la prevención y eliminación de la contaminación en el mar Mediterráneo causada por vertidos desde buques y aeronaves o por incineración en el mar, el Protocolo sobre cooperación para combatir en situaciones de emergencia la contaminación del mar Mediterráneo causada por hidrocarburos y otras sustancias perjudiciales, el Protocolo sobre la Protección del mar Mediterráneo contra la contaminación de origen terrestre, el Protocolo sobre las Zonas Especialmente protegidas y la Diversidad Biológica del Mediterráneo, el Protocolo sobre la protección del mar Mediterráneo contra la contaminación derivada de la exploración y explotación de la plataforma continental y el lecho marino y de su subsuelo, el Protocolo sobre la prevención de la prevención en el mar Mediterráneo causado por movimientos transfronterizos de desechos peligrosos y su eliminación, el Protocolo sobre Gestión integrada de las Zonas Costeras del Mediterráneo y el Acuerdo sobre la conservación de los cetáceos del mar Negro, el Mediterráneo y la Zona Atlántica contigua (ACCOBAMS) de 1996 ${ }^{28}$, que incluye desde 2010 la totalidad de las Zonas Económica Exclusiva de España y Portugal.

Además, en relación con el marco jurídico internacional de protección del medio marino, el Mediterráneo ha sido reconocido como "área especial" de acuerdo con el Anexo I (Reglas para prevenir la contaminación por hidrocarburos, en vigor

\footnotetext{
${ }^{26}$ Sobre incidentes en aguas en torno a Gibraltar, véase Miguel Acosta Sánchez, "Incidentes hispano-británicos en las aguas de la Bahía de Algeciras/Gibraltar, ¿Qué soluciones?”, Cuadernos de Gibraltar/Gibraltar Reports, $n^{\circ} 1,2015$, pp. $171-2018$. Sobre las aguas cercanas a Marruecos, Alejandro del Valle Gálvez" Ceuta, Melilla, Chafarinas, Vélez y Alhucemas: tomar la iniciativa", Boletín Elcano, 2011, no 142, p. 1-10.

${ }^{27}$ Véase Valentín Bou Branch (coord.), José Juste Ruiz (coord.), José Manuel Sánchez Padrón (dir.), Derecho del mar y sostenibilidad ambiental en el Mediterráneo, editorial Tirant lo Blanch, 2014.

${ }^{28}$ En Tarik Atmane en España y Marruecos frente al derecho del mar, Coruña, editorial Netbiblo, 2008.
} 
desde 1983) y también en relación con el Anexo V (Reglas para prevenir la contaminación ocasionada por las basuras de los buques, en vigor desde 2009) del Convenio para prevenir la contaminación por los buques (MARPOL 73/78) ${ }^{29}$. No obstante, en la zona del estrecho de Gibraltar no existe una zona o área marina específica protegida de acuerdo con alguna de las posibilidades existentes en la normativa internacional de protección del medio ambiente marino, salvo aquellas incluidas bajo el marco del derecho de la Unión Europea como mencionaremos más adelante. El área marina protegida por instrumentos internacionales más cercana, al este, sería el conjunto de la isla de Alborán y sus fondos marinos ${ }^{30}$, y al oeste, la zona marina especialmente sensible, las aguas occidentales de Europa, aprobadas en el marco de la OMI en $2004^{31}$.

Con carácter más simbólico que jurídico, como corresponde a una figura cercana al soft law, debemos hacer mención a la Reserva Intercontinental del Mediterráneo Andalucía (España)-Marruecos, Reserva de la Biosfera, reconocida en el plano internacional en el marco del Programa sobre el Hombre y la Biosfera (MaB) de la UNESCO y cumple como finalidad primordial el intento de conciliación de preservación de la diversidad biológica y los recursos biológicos con su utilización sostenible ${ }^{32}$. Aquí, las aguas del estrecho de Gibraltar sirven como eje en la planificación norte sur de los espacios protegidos en Marruecos y Andalucía, remarcadas como zona de transición marina, pero

29 Citado por D. R. Rothwell en "Strait of Gibraltar", Max Planck Encyclopedia of Public International Law, consultada en la página web de Oxford Public International Law, https://opil.ouplaw.com/view/10.1093/law:epi//9780199231690/law-9780199231690-e1172 (consultada por última vez el 2 de agosto de 2019).

30 En 2001 se declaró el conjunto de la isla de Alborán y de sus fondos marinos como Zona Especialmente Protegida de Importancia para el Mediterráneo (ZEPIM), en el marco del Convenio de Barcelona. La Junta de Andalucía, por su parte, declaró en 2003 el "Paraje Natural de Alborán", que comprende el territorio de la isla de Alborán, el islote de la Nube y las aguas y los fondos marinos que las rodean. En el ámbito europeo, el entorno de la isla de Alborán está declarado como Lugar de Interés Comunitario (LIC) dentro de la red Natura 2000 (LIC ES6110015) desde 2006, con una superficie de unas 26.375,44 ha coincidiendo con el Paraje Natural.

31 Una ZMES es aquella que debe ser objeto de protección especial, de acuerdo con las medidas que adopte la OMI, en atención a su importancia por las características ecológicas, socioeconómicas o científicas reconocidas, si tales características pueden sufrir daños como consecuencia de las actividades marítimas internacionales. Las directrices para la designación de una "zona marina especialmente sensible" se adoptaron en la resolución A,982(24) por la Asamblea de la OMI en 2005, titulada "Directrices revisadas para la determinación y designación de zonas marinas especialmente sensibles".

32 Sobre ello, Jesús Verdú Baeza, "El medio ambiente como instrumento de cooperación transfronteriza: la Reserva de la Biosfera Intercontinental del Mediterráneo entre Andalucía y Marruecos", Anuario Español de Derecho Internacional, n² 28, 2012, pp. 397 - 416. 
sin ningún nivel de protección en esta figura, aunque sea de carácter simbólico, de acuerdo con su naturaleza jurídica, al incluir solo los espacios naturales protegidos en el territorio de acuerdo con la normativa interna marroquí o española ${ }^{33}$.

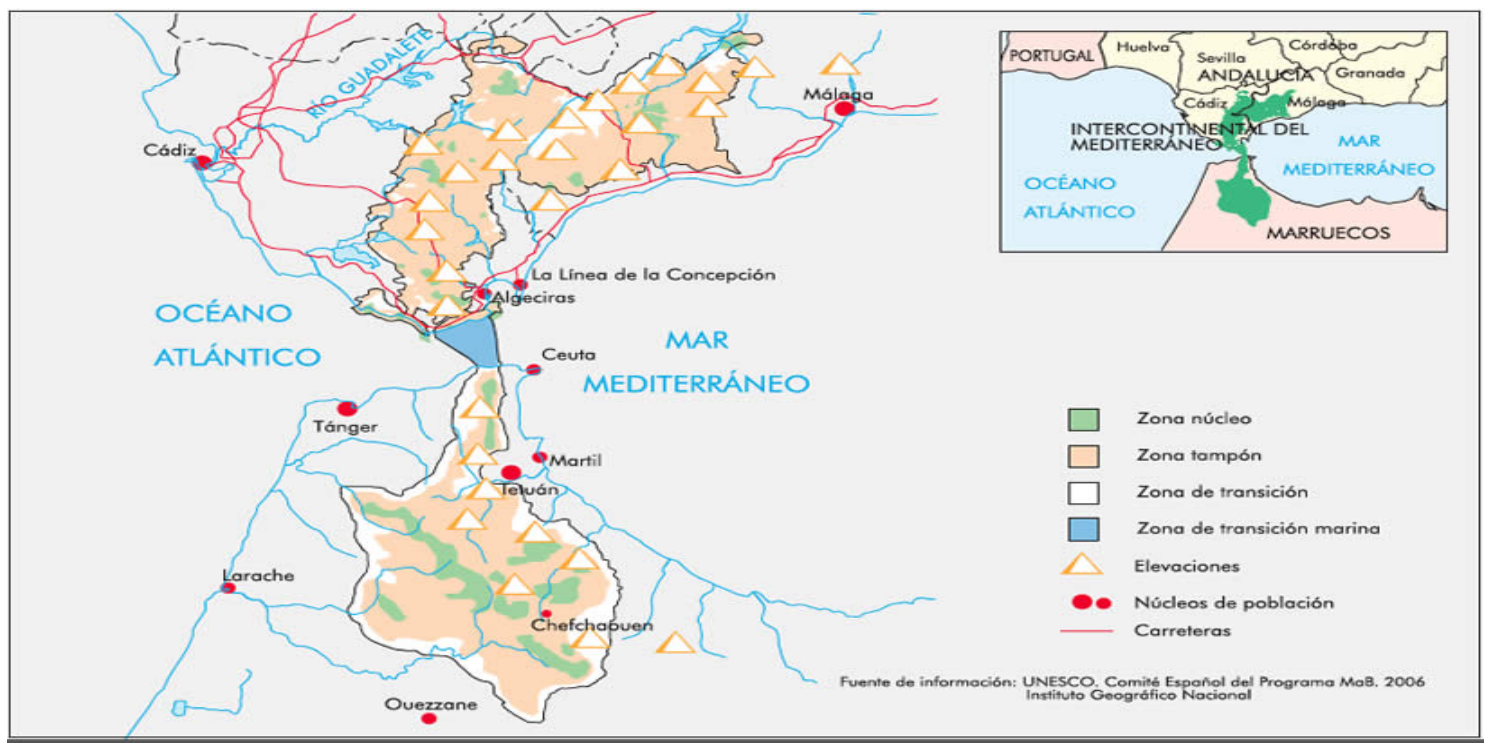

Figura 1. Mapa de la Reserva de la Biosfera Intercontinental del Mediterráneo, obtenida de la ficha de la Red Española de Reservas de la Biosfera.

Fuente: $\quad$ http://rerb.oapn.es/red-espanola-de-reservas-de-la-biosfera/reservasde-la-biosfera-espanolas/mapa/intercontinental-del-mediterraneo/ficha

Motivadas por el alto interés medioambiental de esta zona tan singular, han sido varias las propuestas de la comunidad científica y de la sociedad civil, articuladas

\footnotetext{
${ }^{33}$ La Reserva de la Biosfera Intercontinental del Mediterráneo Andalucía (España)-Marruecos la constituyen en Andalucía los Parques Naturales Sierra de Grazalema, Sierra de las Nieves, El Estrecho y Los Alcornocales, los Parajes Naturales de Los Reales de Sierra Bermeja, Sierra Crestellina, Desfiladero de los Gaitanes y Playa de Los Lances, y los Monumentos Naturales Duna de Bolonia, Pinsapo de las Escaleretas y Cañón de las Buitreras. En Marruecos incluye el Parque Nacional de Talassemtane y los Sitios de Interés Biológico y Ecológico de Jbel Bouhachem, Ben Karrich, Jbel Moussa, Koudiet Taifour, Côte Ghomara, Cirque de Jebha y Lagune de Smir. Véase información en la web de la web de la Consejería de Agricultura, Ganadería, Pesca y Desarrollo Sostenible.

http://www.juntadeandalucia.es/medioambiente/site/portalweb/menuitem.7e1cf46ddf59bb227a9 ebe205510e1ca/?vgnextoid=3f5fa92fa7dbe010VgnVCM1000000624e50aRCRD\&vgnextchanne I=2229b8f8606b8210VgnVCM10000055011eacRCRD\&|r=lang es\#apartado85b26ae7eac7d21 0VgnVCM1000001325e50a (consultada por última vez el 6 de agosto de 2019).
} 
a través de diversas ONGs, para que se proteja el área del estrecho de acuerdo con alguna de las figuras previstas, o bien en la normativa interna española, o bien en la normativa internacional de protección del medio marino, en virtud de los valores naturales del área y el buen número de amenazas presentes ${ }^{34}$.

Parece evidente que la alta conflictividad diplomática, la desconfianza mutua y las controversias jurídicas en torno a la delimitación de espacios marinos son obstáculos prácticamente insalvables en la actualidad para que las partes pudieran hacer una propuesta de figura de área marina protegida con carácter internacional. Incluso, de forma expresa, España ha reconocido que, para evitar conflictos, excluía de la primera propuesta de espacios de la red de Zonas de Especial Protección para las Aves el estrecho de Gibraltar, las islas Chafarinas y el Banco de la Concepción al situarse en espacios marinos reclamados por Gibraltar y Marruecos ${ }^{35}$.

En definitiva, ante la ausencia de un marco internacional amplio que comprenda la totalidad del estrecho de Gibraltar, la protección del medio ambiente queda fragmentada por la normativa interna de los tres Estados presentes y por espacios protegidos en el ámbito nacional (y como veremos, también europeo) sin conexión o coherencia a fines de protección, o como en algún caso, con propósitos fundamentalmente políticos más que medioambientales.

En la orilla sur, en Marruecos, no hay ningún área marina protegida en la zona del estrecho, aplicándose en consecuencia, la normativa general de protección medioambiental (fundamentalmente, la Ley Marco que incorpora la Carta Nacional de Medio Ambiente y Desarrollo Sostenible de 20 de marzo de 2014), que ha sido calificada como obsoleta, incompleta e inadaptada a la evolución socio-económica y tecnológica ${ }^{36}$.

\footnotetext{
${ }^{34}$ Entre las propuestas, la de SEO/Birdlife, financiada por la Unión Europea, que identifica el estrecho de Gibraltar como Área de Importancia para las Aves y la Biodiversidad presentada al Ministerio de Agricultura, Alimentación y Medio Ambiente en 2004. Estas áreas son ya identificadas internacionalmente como herramientas adecuadas para la conservación y son áreas identificadas donde es preciso realizar acciones de conservación efectivas por parte de las administraciones públicas. Véase https://www.seo.org/iba/

También WWF ha propuesto un área marina protegida en el estrecho de Gibraltar. Puede consultarse en: https://www.wwf.es/nuestro trabajo loceanos/areas marinas protegidas/

${ }^{35}$ EL PAÍS, "España descarta tres parques para evitar conflictos diplomáticos", 19 de octubre de 2011.

${ }^{36}$ Rabia M'Rabet Temsamani, El Estrecho de Gibraltar: la protección internacional y nacional de su medio ambiente marino, op. cit., p. 218.
} 
Todavía en la orilla sur, debemos citar en Ceuta el Lugar de Interés Comunitario, Zona Marítimo Terrestre del Monte Hacho (LICES6310002), que abarca el espacio natural marino en torno al límite oriental de la ciudad española en el norte de África. Parece especialmente significativo la aplicación de normativa europea, aprobada por la Comisión, en un área protegida, existiendo una controversia territorial con Marruecos.

En la ribera norte, en Gibraltar, la práctica totalidad de sus aguas marinas está protegida por la normativa interna, gran parte de ella como transposición del derecho de la Unión Europea, y como vamos a ver en el epígrafe siguiente, existe un área marina protegida incluida en la Red Natura 2000 de acuerdo con la Directiva Hábitat, el Lugar de Interés Comunitario (LIC UKGIB0002) Southern Waters of Gibraltar.

En España, el Parque Natural del Estrecho protege el espacio marítimo-terrestre desde la ensenada de Getares (Algeciras) al cabo de Gracia (Tarifa) y se adentra en una franja marina de una milla, que está también catalogado como Zona de Especial Protección para las Aves (ZEPA). También, en el entorno de la Bahía de Algeciras/Gibraltar, debemos citar las Marismas del Río Palmones con una extensión de 113 hectáreas correspondientes a las marismas, el cordón dunar primario y las llanuras de inundación. Este peculiar ecosistema es lugar de descanso y anidamiento de gran cantidad de aves, es por ello que además la zona fue declarada ZEPA y Zona de Especial Conservación (ZEC). Frente a la desembocadura del río Palmones se encuentra el LIC denominado Fondos marinos marismas del río Palmones, de 88 hectáreas de extensión que complementa al paraje natural, protegiéndose el lugar de cría de varias especies de peces y la única colonia de posidonea oceanica de la bahía y, fuera ya de la bahía, al oeste, el Estuario del Río Guadiaro, también ZEPA, incluidos todos ellos en la red Natura 2000.

Finalmente, el LIC Estrecho Oriental (ES6120032), con unas veinticuatro mil hectáreas de superficie marítima en torno a Gibraltar, cuyo significado e interpretación realizaremos en el epígrafe siguiente. 


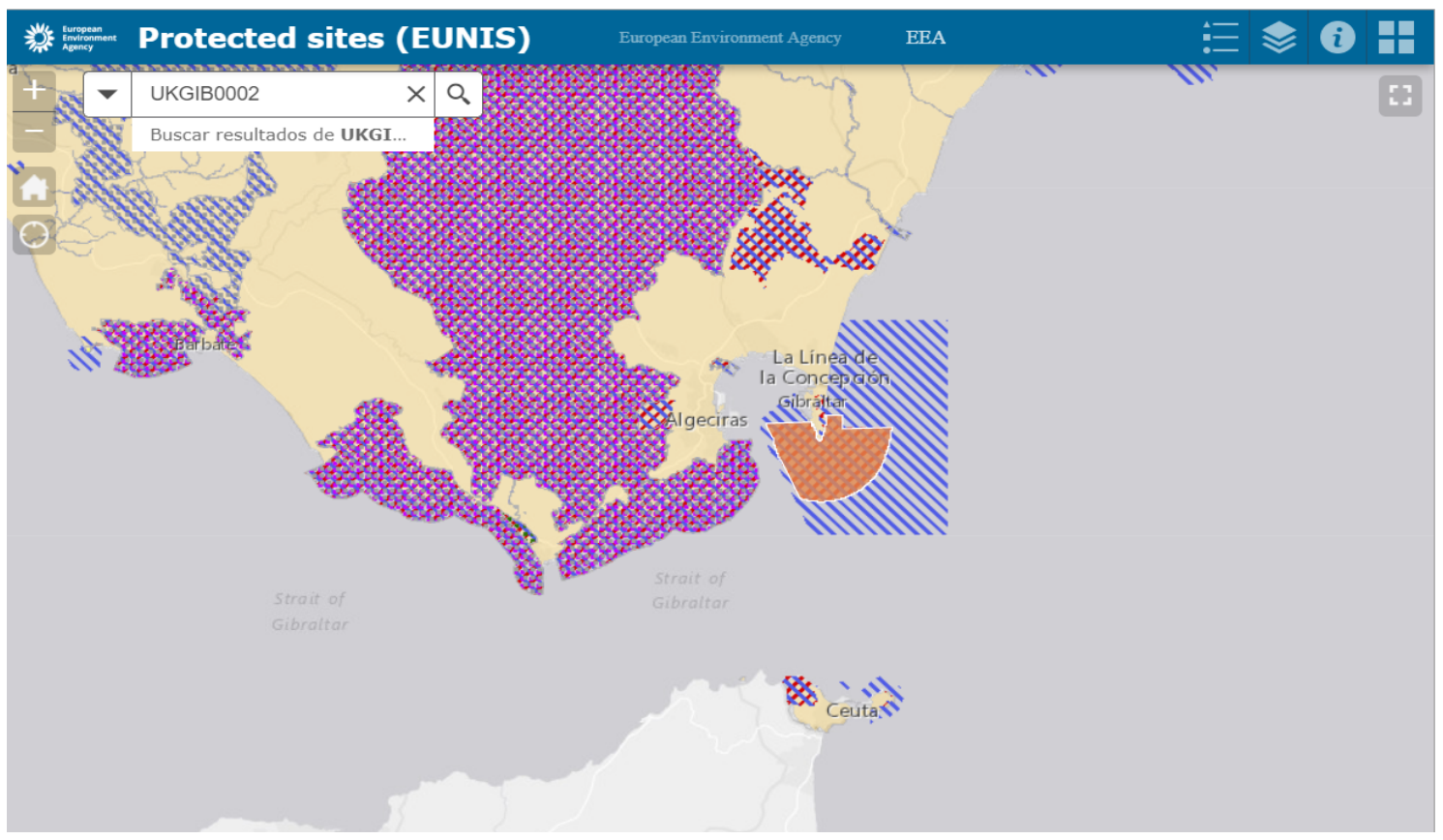

Figura 2. Espacios naturales protegidos en el entorno del estrecho de Gibraltar incluidos en la red Natura 2000.

Fuente: cartografía de la Agencia Europea de Medioambiente, consultada en https://eunis.eea.europa.eu/sites/UKGIB0002\#interactive map (última vez consultada el 6 de agosto de 2019)

En definitiva, como fácilmente puede desprenderse del mapa incorporado como figura número 2 , no existe en la actualidad un área marina protegida que abarque la totalidad de las aguas del estrecho de Gibraltar. Existen ciertas áreas protegidas bajo la legislación nacional (española y gibraltareña) y europea que se incorporan en la red Natura 2000 y que presentan discontinuidades y un solapamiento. Como podemos ver en el mapa, las discontinuidades son tanto en dirección norte-sur como este-oeste.

A pesar de que no hay razones de índole científico que lo justifiquen, los espacios naturales del norte no se vinculan con el área protegida al sur (siendo que la presencia de las mismas especies justifica su necesidad de protección global de acuerdo con las fichas de la red Natura 2000). Mucho más llamativo es el hecho de que el LIC Estrecho Oriental no se conecte con las aguas protegidas del Parque Natural del Estrecho dejando en el oeste de la bahía de 
Algeciras/Gibraltar fuera del marco de protección una pequeña franja que las separa, con el mismo (o mayor) valor ecológico que las aguas protegidas, generando una discontinuidad en la zona protegida solo justificada por la finalidad política del LIC Estrecho Oriental.

Finalmente, nos llama la atención y requerirá un enfoque e interpretación separada en el epígrafe siguiente, como existen dos áreas marinas protegidas superpuestas en torno a las aguas de Gibraltar, una, a propuesta de España (LIC Estrecho Oriental) y otra, a propuesta del Reino Unido (LIC Southern Waters of Gibraltar), que como hemos apuntado en el párrafo anterior, tiene su origen en planteamientos muy alejados de la protección del medio marino.

\section{SOLAPAMIENTO DE ÁREAS MARINAS PROTEGIDAS EN LA BAHÍA DE ALGECIRAS/GIBRALTAR.}

A pesar de la enorme riqueza ambiental de las aguas de la bahía de Algeciras/Gibraltar y de los enormes riesgos presentes, lo cierto es que no han existido mecanismos normalizados de cooperación transfronteriza en cuestiones medioambientales debido a la existencia de múltiples controversias en torno a Gibraltar que desembocan periódicamente en períodos de tensión política.

En la práctica, existen dos zonas bien diferenciadas en la bahía. La mitad oriental queda de facto bajo control gibraltareño, mientras que la occidental es administrada por las autoridades españolas. Esta situación, con ausencia de mecanismos de información o coordinación, es especialmente preocupante al ser una zona de un intenso tráfico marítimo, ya que las instalaciones portuarias cubren prácticamente todo el arco de la bahía con una gran actividad marítimoportuaria. La situación de riesgo es obvia. La inexistencia de canales de navegación ordenados del tráfico marítimo y de coordinación entre las autoridades británicas, gibraltareñas y españolas es un factor claro en la existencia de accidentes marítimos sucedidos en estas aguas hace algunos años ${ }^{37}$.

${ }^{37}$ En 2004 el Spetses, cargado con 139.000 toneladas de crudo colisionó con el crucero Van Gogh. En 2007 se produjo una colisión entre los buques New Flame y el petrolero Torn Gertrud, con 37.000 toneladas de crudo, a resultas del cual el New Flame quedó encallado al sur de Punta Europea. También en 2007, el portacontenedores Veronica B colisionó con el buque Ginga 
En ausencia de un marco de coordinación entre los Estados (España y Reino Unido) y administraciones (Gibraltar) presentes en la Bahía, tanto de seguridad marítima como en asuntos medioambientales, éstos han actuado unilateralmente hasta la fecha. No obstante, tiene gran interés las distintas actuaciones realizadas en el contexto del derecho europeo como único marco de cooperación multilateral. En este sentido, Reino Unido, como Estado miembro y responsable del territorio de Gibraltar obtuvo en 2006 la aprobación por la Comisión en el primer listado de Lugares de Importancia Comunitaria de la región biogeográfica mediterránea del área propuesta, conocida como Southern Waters of Gibraltar que comprende 5.486,50 hectáreas de superficie marítima, esto es, gran parte de sus aguas adyacentes, proyectándose tres millas hacia el este, otras tres millas hacia el sur y la línea equidistante de la interior de la bahía hacia el oeste, en aplicación de la Directiva Hábitat y de la Directiva relativa a la conservación de las aves silvestres, integrando, en consecuencia, esta área marina en la red Natura $2000^{38}$.

Posteriormente, esta zona se ha designado como Zona Marina de Especial Conservación después de la publicación del Plan de Gestión $\left(2011^{39}\right.$ ) y Zona de Especial Protección para las Aves (2012). El objetivo de conservación del Plan de Gestión es asegurar que el estado de las características ambientales incluidas en la normativa europea se mantiene o alcance un estado de conservación favorable de acuerdo con los cambios naturales. Para este fin, se prevé en el Plan de Gestión un programa de monitoreo e investigación científica ${ }^{40}$.

\footnotetext{
Saber. Además de las colisiones, los incidentes de todo tipo son numerosísimos y la lista demasiado larga para trascribirla. A título de ejemplo, en marzo de 2019, Ecologistas en Acción denunciaba que el petrolero Oryx Trader quedó a la deriva en la entrada de la bahía.

${ }^{38}$ Decisión de la Comisión de 19 de julio de 2006, 2006/613/CE.

39 Orden de 9 de marzo de 2011 del Ministro de Medio Ambiente de Gibraltar (Gibraltar Gazette $\mathrm{n}^{\circ}$ 3839, de 10-3-2011)

40 Consultado el Plan de Gestión en la página web del Gobierno de Gibraltar. https://www.gibraltar.gov.gi/new/sites/default/files/1/15/Southern Waters of Gibraltar Manage ment Scheme 2012.pdf (última vez consultada el 6 de agosto de 2019).
} 


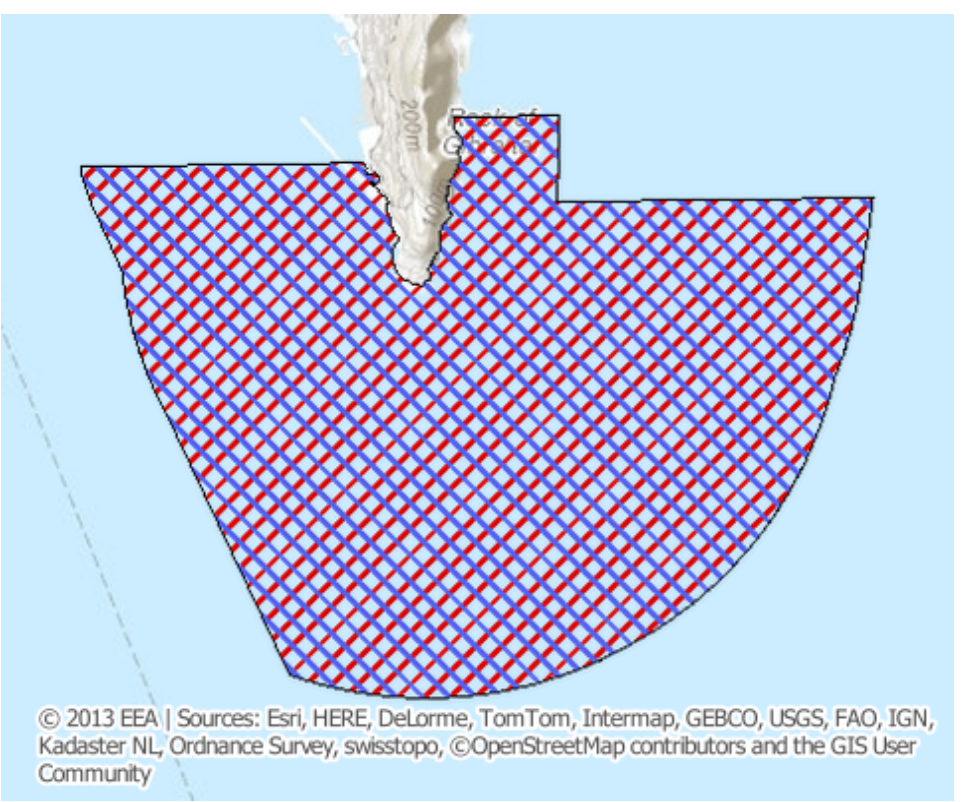

Figura 3. Delimitación geográfica deI LIC Southern Waters of Gibraltar

Fuente: Cartografía de la Agencia Europea de Medioambiente, consultada en https://eunis.eea.europa.eu/sites/UKGIB0002\#interactive map (última vez consultada el 6 de agosto de 2019)

El reconocimiento por parte de la UE de este espacio marino protegido bajo la normativa ambiental europea no puede ser considerado de forma clara e indubitada como un reconocimiento jurídico expreso de la titularidad soberana de las aguas para el Reino Unido o de la jurisdicción de Gibraltar frente a los argumentos españoles en la controversia sobre las aguas. No obstante, es cierto que los matices son múltiples $\mathrm{y}$, en cualquier caso, no hay ninguna duda de que la aprobación refuerza la posición británica, debilitando los argumentos españoles.

Por ello, la respuesta española ha sido doble ${ }^{41}$. Por una parte, se presentó una objeción por escrito a modo de salvaguarda preservando la interpretación española de los términos de cesión del territorio sin aguas territoriales, que no llegó a figurar en la Decisión de la Comisión. Por otra parte, y con mayor

41 Jesús Verdú Baeza, "La doble declaración de Lugares de Interés Comunitario y la superposición de zonas marinas protegidas en aguas de Gibraltar, ¿una nueva controversia?, Revista Española de Derecho Internacional, 2009, 1, LXI, pp. 286 - 291, 
significado, se tomó la iniciativa de proponer en la segunda lista actualizada de LICs de la región biogeográfica mediterránea una zona marítima bajo la denominación de Estrecho Oriental, de 34.000 hectáreas, que se superpone en su totalidad sobre el LIC gibraltareño, y que finalmente fue aprobada por la Decisión de la Comisión el 12 de diciembre de $2008^{42}$.

Frente a esta declaración, tanto Gibraltar como el Reino Unido buscaron anular la declaración del LIC propuesto por España a través de acciones judiciales ante los órganos jurisdiccionales europeos, si bien, con estrategias jurídicas y procesales diferentes, pero que no lograron tener éxito, al no entrar en ningún procedimiento en el fondo del asunto. En primer lugar, el Gobierno de Gibraltar solicitó la anulación parcial del LIC Estrecho Oriental solo en relación con el espacio marino del área protegida que se solapaba con aguas bajo jurisdicción gibraltareña (Gibraltar British Territorial Waters). El Tribunal General mediante Auto de 24 de mayo de 2011 declaró la inadmisibilidad del recurso, pudiéndose interpretar de la lectura de la resolución que tal vez hubiera podido prosperar el recurso de haber solicitado la anulación total del LIC Estrecho Oriental (Asunto T-176/09, Gibraltar/Comisión) al no tener capacidad el Tribunal para reajustar la dimensión de un LIC debidamente aprobado por la Comisión que debe ser considerado inseparable, al carecer de bases científicas de índole ambiental que pudieran justificar la pervivencia de un área protegida modificada por criterios jurídicos. Interpuesto recurso de casación, este fue desestimado mediante Auto de fecha 12 de julio de 2012 (Asunto C - 407/11 P, Gibraltar/Comisión, España y Reino Unido).

Por su parte, el Reino Unido interpuso un recurso de anulación ante el Tribunal General (asunto T-115/10, Reino Unido/Comisión) frente al tercer listado de LICs de la región biogeográfica mediterránea aprobado por Decisión de la Comisión el 22 de diciembre de 2009 (Decisión 2010/45/UE ${ }^{43}$ ), alegando que el LIC Estrecho Oriental propuesto por España incluye una zona de aguas territoriales británicas de Gibraltar y una zona de alta mar. Este recurso fue declarado inadmisible por razones de índole formal al considerar el Tribunal que la tercera

\footnotetext{
42 Decisión 2009/45/UE de la Comisión de 12 de diciembre de 2008, por la que se adopta, de conformidad con la Directiva 92/43/CEE del Consejo, una segunda lista actualizada de lugares de importancia comunitaria de la región biogeográfica mediterránea, $D O$ L 43/393 de 13-2-2009. ${ }^{43}$ DO 2010, L 30, p. 322.
} 
lista se limitaba a confirmar la segunda, de 2008, que incluyó por primera vez el LIC impugnado y que no fue recurrida por el Reino Unido en tiempo y forma en su momento procesal oportuno. Planteado recurso de casación, éste también fue desestimado por los mismos argumentos mediante Sentencia del Tribunal de Justicia (Sala Tercera) de 29 de noviembre de 2012, (Asunto C-416/11 P, Reino Unido/Comisión), igualmente por las consideraciones formales anteriormente mencionadas, sin entrar en el fondo del asunto.

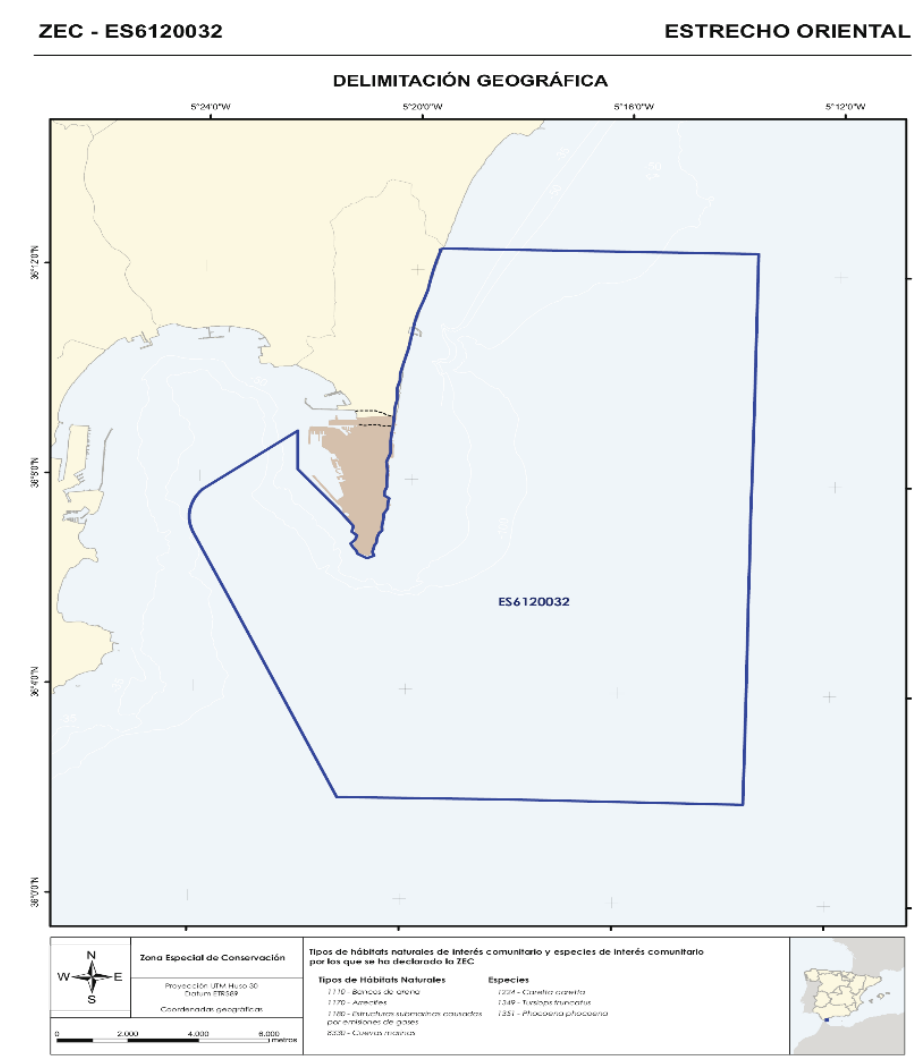

Figura 4. Delimitación geográfica del LIC Estrecho Oriental.

Fuente: Real Decreto de 30 de noviembre de 2012, BOE n 289, de 1-12-2012.

Así pues, se da la paradójica situación, única en la red Natura 2000, en la que un área marina protegida bajo la responsabilidad de un Estado miembro se solapa y encierra en su totalidad otra área marina protegida bajo la responsabilidad de un Estado miembro diferente. No es infrecuente el solapamiento de espacios protegidos, pero en la práctica, estos se producen 
entre diferentes instrumentos jurídicos, nacionales e internacionales, pero bajo responsabilidad de los mismos Estados ${ }^{44}$. No hemos encontrado en la casuística internacional o europea un caso como el que describimos, en el que un área marina protegida engloba en su totalidad otra área marina protegida de un Estado diferente.

En noviembre de 2012, este espacio, LIC Estrecho Oriental, fue declarado por España Zona Especial de Conservación (ZEC), dentro del plazo de seis años previsto en la Ley del Patrimonio Natural y de la Biodiversidad ${ }^{45}$, aprobándose sus correspondientes medidas de conservación ${ }^{46}$. En el Decreto se incluyen medidas reguladoras de los usos y actividades que deberán aplicarse en el ámbito de la ZEC Estrecho Oriental, con el fin de que su ejercicio sea compatible con los objetivos de conservación establecidos en el plan de gestión, en concreto, sobre la actividad pesquera, acuicultura, acceso a recursos genéticos, ocupación del espacio protegido y regulación de usos y aprovechamientos extractivos y energéticos, regulación de la navegación, prevención de la contaminación, basura marina, conducción y cableado submarino, actividades de defensa nacional y seguridad pública, bunkering, actividades recreativas y observación de especies silvestres, investigación científica, prevención de la contaminación acústica y, finalmente, labores de vigilancia, inspección y control.

En relación con la propuesta española de esta área marina protegida, en nuestra opinión, destacan dos circunstancias. La primera es relativa a los criterios de delimitación, al centrarse fundamentalmente en las aguas que rodean al Peñón de Gibraltar y que comparten las características ecológicas y ambientales del resto de la bahía de Algeciras/Gibraltar que quedan fuera del espacio protegido, siendo, en consecuencia, incongruente en términos ambientales. Las especies marinas y los ecosistemas de los diferentes anexos de la Directiva Hábitat a proteger incluidos en la ficha española son en gran parte los mismos que están en las aguas de toda la bahía y en las del estrecho. En principio, parecería coherente desde una perspectiva ambiental que el espacio protegido cubriera un área marina más amplia, esto es, la existente desde el LIC Parque Natural del

\footnotetext{
${ }^{44}$ Deguinet, M, et al., "Measuring the extent of overlaps in protected area designations." PloS one, 2017.

${ }^{45}$ Ley 42/2007, de 13 de diciembre, BOE no 299, de 14-12-2007.

${ }^{46}$ Real Decreto de 30 de noviembre de 2012, BOE n 289 , de 1-12-2012.
} 
Estrecho al oeste, el LIC Fondos marinos de las marismas del río Palmones al norte y el LIC Estrecho Oriental al este, otorgando una protección global, ordenada y sistemática a toda la zona marina que presenta las mismas riquezas y valores ecológicos, además de los mismos problemas, amenazas y desafíos. Pudiéramos comprender que la unión hacia el sur con el LIC Zona Marítimo Terrestre del Monte Hacho en Ceuta plantea problemas específicos y complejos al incluir una parte significativa del estrecho de Gibraltar.

En segundo lugar, Estrecho Oriental es un área sobre el que España no ejerce de facto ningún tipo de control, más allá de la presencia puntual de buques de Estado, fundamentalmente de la Guardia Civil o de la Marina, que producen incidentes recurrentes cada cierto tiempo y que, normalmente, abandonan la zona una vez identificados y requeridos para ello por los buques británicos o gibraltareños. Parece bastante obvio que España no está en condiciones de cumplir las obligaciones que se derivan de la normativa europea de protección ambiental si no ejerce ningún control de la zona. A modo de resumen y sin ánimo de exhaustividad, España no controla ni los vertidos de aguas residuales desde Gibraltar, ni las actividades portuarias (incluido el fondeo) en estas aguas, no tiene capacidad alguna en lo relativo a la planificación de desarrollos urbanísticos con terrenos ganados al mar desde el peñón que generarían alteración de las dinámicas litorales, no ejerce competencias sobre embarcaciones militares, de aduanas, de policía, sobre actividades pesqueras, sobre cruceros turísticos, sobre buques de avistamiento de cetáceos, etc. Recordemos que en estas aguas se han producido en fechas relativamente cercanas accidentes marítimos, como el citado del New Flame o el encallamiento del Fedra y el Samathraki, con muy poca diferencia temporal, en los acantilados de Punta Europa al sur de Gibraltar, incidentes en los que las autoridades españolas no han participado.

Por otra parte, también nos llama la atención que el Real Decreto 1620/2012, de 30 de noviembre, por el que se declara ZEC el LIC Estrecho Oriental, se aprobara a propuesta del Ministro de Asuntos Exteriores y de Cooperación, en sustitución del Ministro de Agricultura, Alimentación y Medio Ambiente ${ }^{47}$.

\footnotetext{
47 Abstención motivada formalmente por concurrir causa de abstención de las previstas en el artículo 28.2 de la Ley 30/1992, de 26 de noviembre, de Régimen Jurídico de las Administraciones Públicas y del Procedimiento Administrativo Común. Real Decreto 1618/2012, de 30 de noviembre. $B O E n^{\circ} 289$, de 01-12-2012. La causa de la abstención puede estar en la
} 
Finalmente, el complejo episodio del superpetrolero iraní Grace 1 nos sirve como ejemplo bastante claro de la ausencia de controles soberanos españoles en este espacio marino protegido en torno a Gibraltar. En estas aguas, marines británicos y agentes gibraltareños detuvieron en julio de 2019 , a solicitud de los Estados Unidos, un petrolero iraní, denominado Grace 1, (que fue liberado algo más de un mes después) por el supuesto incumplimiento del Reglamento $36 / 2012$ relativo a las medidas restrictivas por el conflicto de Siria, un país sujeto a sanciones de la UE, abriendo una preocupante crisis internacional con repercusiones en el estrecho de Ormuz ${ }^{48}$. La detención del buque fue realizada sin ninguna actividad de las autoridades marítimas españolas que, por cierto, ni siquiera fueron avisadas por los Estados Unidos. España sí anunció la presentación de una queja formal del Ministerio de Asuntos Exteriores ${ }^{49}$.

Pues bien, el buque fondeado como consecuencia de la intervención británica en las aguas teóricamente doblemente protegidas de Gibraltar estaba cargado con 1,2 millones de barriles de crudo. Es bastante evidente que esta circunstancia supone per se un enorme riesgo en una zona protegida ya que un vertido al mar causaría una catástrofe medioambiental de enormes proporciones. Además, de las informaciones que se han ido publicando, el buque carece de bandera, al negar Panamá, pabellón que ostentaba oficialmente, que estuviera bajo su jurisdicción, lo msimo que Islas Marshall, su primer pabellón ${ }^{50}$. Parece claro que de ejercer en la práctica España jurisdicción real sobre el área marina protegida, tal y como oficialmente se mantiene, y siendo que el fondeo del superpetrolero en estas aguas podría entrar en contradicción con lo dispuesto en el Real Decreto 1620/2012, de 30 de noviembre, por el que se declara ZEC

relación del entonces Ministro de Agricultura, Alimentación y Medio Ambiente con actividades privadas de suministro de combustibles a buques en la zona del estrecho de Gibraltar. EL PAÍS, "Abstenciones en el Consejo de Ministros de España", 16 de octubre de 2016. EL DIARIO, "Sáenz de Santamaria, De Guindos y Cañete se han tenido que abstener en decisiones del Gobierno por posible incompatibilidad", 16 de junio de 2013.

${ }^{48}$ Días después de la detención del Grace 1 en Gibraltar, un buque de bandera británica, el Stena Inpero, fue apresado por fuerzas iraníes en el estrecho de Ormuz. Reino Unido ha desplazado una flota de protección a sus buques en un paso estratégico del transporte internacional de hidrocarburos.

${ }^{49}$ EL PAÍS, "España planea una queja ante Londres por el incidente del petrolero interceptado por Gibraltar", 4 de julio de 2019.

${ }^{50}$ EL PAÍS, "El Grace 1, un conflicto diplomático y una bomba de relojería en el Estrecho", 16 de agosto de 2019. 
el LIC Estrecho Oriental, es de suponer que España hubiera debido intervenir ordenando las medidas adecuadas.

En resumen, nos parece bien evidente que la pretensión de España de incluir en el listado de LICs un espacio marino en torno a Gibraltar, que incluyera en su totalidad el LIC gibraltareño, con las severas incongruencias de tipo ambiental que hemos mencionado en aguas donde no hay presencia habitual, ni control de las autoridades españolas, carece de una voluntad real de protección ambiental. Por el contrario, tiene, en nuestra opinión, una finalidad fundamentalmente política, esto es, reforzar su, manifiestamente débil, tesis jurídica en relación con las aguas de Gibraltar y reaccionar ante la previa declaración del LIC Southern Waters of Gibraltar y que pudiera ser interpretada como un respaldo europeo a la posición británica y gibraltareña en la controversia sobre las aguas.

\section{EL BREXIT COMO AMENAZA A LA PROTECCIÓN AMBIENTAL}

Lo cierto es que esta teórica doble protección por parte del Reino Unido y de España sobre las mismas aguas no ha tenido como resultado práctico una mejor protección del medio ambiente marino sometido a múltiples factores de riesgo y amenazas. Es, desafortunadamente, un buen ejemplo el caso del alga invasora introducida a través de descargas de agua de lastre insuficientemente controladas de un buque fondeado en la bahía. Doble teórica protección jurídica no ha equivalido en la práctica a una doble protección ambiental. Tal vez, lo contrario, podemos afirmar que ha existido una menor protección al tratarse de aguas en litigio, con presencia, regular o irregular, de varias administraciones, por lo que parece necesario vías de concertación y armonización de la protección ambiental. Sin embargo, los Estados involucrados no han encontrado las necesarias fórmulas de coordinación para abordar los problemas ambientales, e íntimamente relacionados, de pesca y la seguridad marítima ${ }^{51}$.

No obstante, lo cierto es que la membresía común de los Estados, España y Reino Unido y de Gibraltar, como territorio europeo cuya política exterior depende del Reino Unido, en la Unión Europea ha sido un factor, algunas veces

\footnotetext{
51 Vid. Inmaculada González García., "La pesca y el medio ambiente en las aguas de Gibraltar: la necesaria cooperación hispano-británica en el marco de la Unión Europea", Cuadernos de Gibraltar/Gibraltar Reports, n 1, 2015, pp. $149-170$.
} 
determinante, de desactivación de crisis ambientales con origen en las aguas en litigio. Si, en general, las instituciones europeas han sido un marco apropiado de tratamiento de ciertas controversias ${ }^{52}$, en particular, en cuestiones medioambientales, su papel ha sido especialmente relevante. En cierto modo, las instituciones europeas han logrado amortiguar el peligroso riesgo de escalada presente en algunos brotes de conflictos que han ido surgido periódicamente en torno a las controversias existentes.

En este sentido, es un buen ejemplo la crisis del verano de 2013 desencadenada cuando el Gobierno de Gibraltar decidió instalar un conjunto de setenta y cinco arrecifes artifíciales en aguas muy degradadas, al norte de la pista del aeropuerto y cercanas a la frontera española, para la mejora de la biodiversidad, y, por lo tanto, de las condiciones de pesca ${ }^{53}$. La respuesta del Gobierno español, que había puesto fin al existente Foro tripartito de Diálogo, fue manifiestamente desproporcionada (motivada por factores de política interna cuyo análisis desborda el objeto de este trabajo), endureciendo los controles fronterizos en la Verja hasta límites sin precedentes y la utilización de un lenguaje agresivo y provocador que condujo a un escenario de confrontación con resultado incierto. La intervención de la UE fue determinante para reconducir una situación extremadamente conflictiva. Por una parte, sirvió como cauce institucional para canalizar los argumentos contradictorios de las partes, amortiguando el nivel de enfrentamiento. Por otra, las instituciones europeas, con un enfoque, en principio, objetivo y sin entrar directamente en la causa profunda de las controversias (falta de delimitación jurídica de los espacios marinos de la bahía), recondujeron los hechos conforme al derecho europeo, logrando separar en relación con los hechos denunciados los elementos políticos de los jurídicos, únicos tenidos en consideración. Así, en julio de 2014, la Dirección General de Medio Ambiente de la Comisión de la UE dictaminó que, tras las quejas recibidas por parte de España, no fue posible identificar una violación de la normativa medioambiental comunitaria con respecto a las actividades de bunkering, los proyectos de rellenos de Eastside y Sovereign Bay ni tampoco, en especial, el

\footnotetext{
52 Véase Pedro Manuel Quesada López y Rabia M'Rabet, "Reflexiones jurídicas en torno al posible papel mediador de la Unión Europea en el contencioso de Gibraltar", Anuario Español de Derecho Internacional, vol. 33, 2017, pp. 337 - 368.

${ }^{53}$ Sobre esta crisis, Alejandro del Valle Gálvez, "La crisis de Gibraltar y las medidas, opciones y estrategia de España”, Real Instituto Elcano, ARI 32/2013, 19-08-2013.
} 
sistema de arrecifes artificiales de la parte noroeste de las Aguas Territoriales Británicas de Gibraltar, recibiendo ambas partes un informe con la evaluación y las conclusiones ${ }^{54}$. Esta intervención contribuyó de forma decisiva a la desactivación de una controversia, que, como hemos mencionado, alcanzó un nivel de confrontación política de unos niveles desconocidos hasta la fecha y que, de no haber sido por la intervención europea, probablemente hubieran podido arrastrar a las partes a una crisis de mayor envergadura y de consecuencias imprevisibles.

En definitiva, ante la existencia de unas controversias, jurídicas en su inicio, pero que han desembocado en un desencuentro político permanente, de una falta de confianza mutua y de un clima de tensión larvado, pero fácilmente incendiable, la pertenencia común a la UE ha logrado servir como un elemento de dulcificación de las relaciones, de factor de desactivación, de foro de encuentro y tratamiento de ciertas situaciones conflictivas potencialmente peligrosas.

En este sentido, la retirada del Reino Unido y, en consecuencia, de Gibraltar, de la Unión Europea (Brexit), presenta un preocupante conjunto de incertidumbres en relación con la protección ambiental del área marina en torno a Gibraltar. Parece ya un lugar común que el proceso de Brexit conduce a escenarios difíciles de prever en un marco de gran inestabilidad política, especialmente en el Reino Unido. Pocos autores cualificados se atreven ya a prever escenarios futuros, y, por el contrario, la mayoría coincide en que todo parece ya posible, incluso una salida sin acuerdo.

En este contexto, es una pretensión de este trabajo identificar las consecuencias de la salida del Reino Unido de la UE en relación con la protección del medio marino en torno en Gibraltar. En primer lugar, y a falta de un posible acuerdo entre las partes, el principal efecto es que el LIC y ZEC Southern Waters of Gibraltar dejará de pertenecer a la red Natura 2000. Hasta la fecha, la

\footnotetext{
${ }^{54}$ Extremo confirmado por el Comisario europeo de Medio Ambiente en respuesta escrita de 25 de julio de 2014 a pregunta (E-006075-14) de la europarlamentaria Catherine Bearder del grupo ALDE (Alianza de Liberales y Demócratas para Europa): "La Comisión ha considerado toda la información y el punto de vista aportados por ambos estados miembros $y$, con base en las pruebas aportadas, no ha sido capaz de identificar incumplimiento alguno de la normativa medioambiental de la UE".

Consultada en la web del Parlamento Europeo http://www.europarl.europa.eu/doceo/document/E-8-2014-006075 EN.html?redirect (última consulta el 13 de agosto de 2019).
} 
conservación del área marina protegida es una responsabilidad compartida entre el Reino Unido y Gibraltar de una parte, y la UE, siendo ésta la que estructura y da coherencia al ordenamiento ambiental, básicamente mediante la Directiva Hábitat, la Directiva relativa a la conservación de las aves silvestres, la Directiva Marco sobre la Estrategia Marina y la Estrategia de Biodiversidad. Además, las instituciones europeas son las competentes en el control, examen, inspección y valoración del cumplimiento de la normativa europea, así como en la resolución de controversias en relación con dicha normativa ambiental, con un papel primordial por parte del TJUE. El Reino Unido y Gibraltar, en el marco de sus competencias constitucionales, tendrán que implementar el conjunto de normas internas que sustituyan el acervo comunitario en el ámbito de protección ambiental marina después del Brexit. Siendo, en general, mucho más estricta la normativa ambiental europea que la doméstica, deberán decidir el nivel de protección ambiental y que tipo de figura de área marina protegida podría articularse ${ }^{55}$. Por supuesto, la primera opción a realizar en relación con las áreas marinas protegidas es decidir el reino Unido y Gibraltar si quieren que continúen con una figura de protección o no. Si la respuesta es positiva, se debe plantear como remplazar con normativa exclusivamente interna el acervo europeo en esta materia. Es posible que la sustitución normativa se realice sin problemas y que las técnicas legales sean equivalentes a las europeas, en aplicación del principio de no regresión que, esperamos, debe inspirar todo el proceso, pero la principal cuestión es que Southern Waters of Gibraltar dejará de ser un área protegida en un marco internacional multilateral para ser un área marina protegida en el ámbito interno. Hay una posible opción en el marco del Consejo de Europa, la red emerald ${ }^{56}$, que constituye un conjunto de áreas de interés de especial conservación como herramienta de los Estados miembros para conseguir los objetivos de la Convención de Berna o Convenio relativo a la conservación de la vida silvestre y del medio natural en Europa. Ahora bien, su posible inclusión provocará, sin duda, una previsible reacción española, por lo que, a la hora actual, es difícil prever el interés británico en abrir nuevas vías de conflicto. No

\footnotetext{
55 J. L. Solandt, B. Stewart y A. Puritz, "Perspective: What does Brexit Mean for UK MPAs?", 1804-2017, MPA News, https://mpanews.openchannels.org/news/mpa-news/perspective-whatdoes-brexit-mean-uk-mpas, (consultado por última vez el 18 de agosto de 2019).

${ }^{56}$ Más información en: https://www.coe.int/en/web/bern-convention/emerald-network (última vez consultada el 18 de agosto de 2019)
} 
obstante, el peso político del Consejo de Europea y la arquitectura jurídica e institucional de la red emerald en relación con la protección del medio no es, en absoluto, comparable con la significación y alcance de la red Natura 2000.

Por ello, y como segunda consecuencia del Brexit, el LIC y ZEC Estrecho Oriental será la única área marina protegida en un marco internacional en esta zona ecológicamente tan rica, pero tan compleja en términos jurídicos y políticos. Como hemos tratado de argumentar antes en este trabajo, es nuestra opinión que este espacio protegido tiene un diseño fundamentalmente político, estando muy lejos de proporcionar un marco de una mayor protección ambiental al carecer de una coherencia lógica con los espacios adyacentes y, lo que es más importante, al no tener el Estado teóricamente responsable, España, un control y una presencia efectiva en estas aguas.

El tercer y último efecto del Brexit será la desaparición de la UE como marco institucional común de los Estados presentes en la bahía y que, como hemos expuesto, ha venido hasta la fecha cumpliendo el papel de amortiguación de las crisis y proporcionando un cauce de tratamiento de las controversias políticas y jurídicas en este espacio tan sensible y singular.

\section{CONCLUSIONES}

El área del estrecho de Gibraltar es uno de los espacios con mayor biodiversidad y riqueza ecológica del planeta por sus especiales características geofísicas y el fenómeno de intercambio de masas de agua con distinta salinidad y temperatura entre el mar Mediterráneo y el océano Atlántico y la retención de nutrientes procedentes de la cuenca mediterránea, además de ser un corredor privilegiado de rutas migratorias tanto de aves como de especies marinas.

Tres Estados están presentes en el área, España, Marruecos y el Reino Unido y un territorio no autónomo dependiente del Reino Unido, Gibraltar. Sus espacios marinos en el estrecho no están delimitados debido a un complejo conjunto de controversias políticas y jurídicas. Además, entre estos Estados no existen marcos institucionales de cooperación transfronteriza.

El estrecho de Gibraltar es una zona especialmente amenazada por un gran número de factores, entre los que destaca el enorme número de buques que 
transitan en una de las principales vías intercontinentales de navegación marítima. Además, en ambas orillas se han puesto en marcha modelos de crecimiento basados en desarrollos industriales y portuarios con un severo impacto ambiental, que, a su vez, multiplican las amenazas y problemas existentes.

El régimen jurídico de navegación en el estrecho regulado en el Convenio de Naciones Unidas sobre Derecho del Mar, paso en tránsito, limita seriamente las posibilidades de control e intervención en materia ambiental de los Estados ribereños.

Por todo ello, sería deseable la existencia de una figura de protección ambiental en un marco internacional que creara un área marina protegida entre las diferentes posibilidades existentes en el derecho internacional del medio ambiente que otorgara una coherencia en la protección y proveyera de cauces institucionalizados de cooperación entre los Estados. No existiendo tal figura global o regional, destaca la existencia hasta la fecha de varias áreas marinas protegidas bajo el derecho europeo integradas en la red Natura 2000. La previsible salida del Reino Unido de la UE tendrá un impacto severo en este marco de protección ambiental. Por una parte, supondrá la desaparición de la red de un área, muy valiosa en términos ecológicos, Southern Waters of Gibraltar, que es de suponer que continuará siendo una zona protegida, pero en un marco nacional. Por otra, en la red europea continuará un área marina protegida, Estrecho Oriental que, solapando el área marina protegida citada anteriormente, abarca un importante espacio marino bajo teórica responsabilidad de España.

La gran paradoja es que España ha dejado fuera del marco de protección aguas de la bahía y del estrecho sobre las que ejerce un control efectivo y que comparten los valores ecológicos con las aguas que rodean Gibraltar y, sin embargo, se compromete a proteger frente a las instituciones europeas aguas en torno a la roca, Estrecho Oriental, sobre las que no ejerce ningún tipo de control.

Una vez fuera el Reino Unido de la UE, si finalmente se consuma el Brexit, es de prever que la situación descrita no facilitará la cooperación en materia medioambiental, sino que, por el contrario, pudiera servir como factor de 
exacerbación de la inestabilidad de la zona y se carecerá de un marco internacional que, como ha desempeñado la UE hasta la fecha, ayude a canalizar las controversias, apaciguando las desavenencias y la falta de confianza mutua entre las partes.

\section{BIBLIOGRAFÍA}

Aguilar, A. y Borrel, A., "Open-boat whaling on the Straits of Gibraltar ground and adjacent waters". Marine Mammal Science, 2007, vol. 23, no 2, pp. 322-342.

Atmane, Tarik, España y Marruecos frente al derecho del mar, Coruña, editorial Netbiblo, 2008.

Bernal-Casasola, Dario, "Whale Hunting in the Strait of Gibraltar during the Roman Period", SAA Archaeological Record, 2018.

Bou Franch, Valentín, La navegación por el mar territorial, incluido los estrechos internacionales y las aguas archipelágicas, en tiempo de paz, Iberediciones, Madrid, 1994.

Cabello Medina, Jesús, "Parque Natural del Estrecho, un nuevo futuro" en Medio Ambiente, Consejería de Medio Ambiente de la Junta de Andalucía, $n^{\circ} 43$, primavera, 2003.

Cepillo Galvin, Miguel Ángel, "El dispositivo de separación del tráfico marítimo en el estrecho de Gibraltar", en SOBRINO HEREDIA, J. M. (dir.), La contribución de la convención de Naciones Unidas sobre derecho del mar a la buena gobernanza de los mares y océanos, Editoriales Scientifica, Nápoles, vol. 2, 2014, pp. $731-745$.

Cestino Pérez, Joaquín, El estrecho, treinta siglos de historia en Gibraltar, Tánger, Tarifa, Ceuta y Algeciras, editorial Arguval, Málaga, 2004.

Deguinet, $M$, et al., "Measuring the extent of overlaps in protected area designations." PloS one, 2017.

Del Valle Gálvez, Alejandro, "Maritime Zones around Gibraltar", Spanish Yearbook of International Law, n² 21, 2017, pp. $311-326$. 
- "La crisis de Gibraltar y las medidas, opciones y estrategia de España", Real Instituto Elcano, ARI 32/2013, 19-08-2013.

Fernández Casado, M. "Aproximación al estudio de las poblaciones de las diferentes especies de cetáceos en el estrecho de Gibraltar: resultados preliminares" en Revista de Estudios Campogibraltareños, Almoraima, n 23, 2000 , pp. $209-218$.

Fernández Sánchez, Pablo Antonio, "La controversia sobre la titularidad jurídicointernacional de los espacios jurídicos adyacentes a Gibraltar, Revista Española de Derecho Internacional, vol. 67, n² 2, 2015, pp. $13-47$.

García Gómez, José Carlos, "Adiciones a la fauna de opistobranchios del Estrecho de Gibraltar" en Iberus, v. 6, 1987, pp. 197 - 209.

González García, Inmaculada, "La pesca y el medio ambiente en las aguas de Gibraltar: la necesaria cooperación hispano-británica en el marco de la Unión Europea”, Cuadernos de Gibraltar/Gibraltar Reports, n 1, 2015, pp. 149 - 170.

Gutiérrez Castillo, Víctor Luis, "Estudio del régimen jurídico del Estrecho de Gibraltar: conflictos de soberanía, espacios marinos y navegación”, en Del Valle Gálvez, A., El Hougaigui, R. y Acosta Sánchez, M., Las dimensiones internacionales del Estrecho de Gibraltar, Dykinson, Madrid, 2006.

GIBRALTAR ORNITHOLOGICAL AND NATURAL HISTORY SOCIETY (GONHS), The Habitats Directive and Gibraltar: Implementation in Gibraltar of Council Directive on the Conservation of Natural Habitats and of Wild Flora and Fauna, Gibraltar, 1994.

López Martín, A. G., La navegación por los estrechos: geoestrategia y derecho, Dykinson, Madrid, 2008.

Mangas Martín, Araceli., "Gibraltar: Adjacent Waters to the territory Yielded by Spain" en FERNÁNDEZ SÁNCHEZ, P. A., New Approaches to the Law of the Sea, Nova Science Publishers, 2017, pp. $31-45$.

Serrano, Martín, "Un alga asiática invade el estrecho de Gibraltar y pone en grave peligro su ecosistema", Reach/Alcance, n 16, agosto de 2019, p. 8.

M'Rabet Temsamani, Rabia, El Estrecho de Gibraltar: la protección internacional y nacional de su medio ambiente marino, editorial Dykinson, Madrid, 2018. 
Pacha Vicente, Esteban, Propuesta de designación de Zona Marina Especialmente Sensible del Estrecho de Gibraltar y Golfo de Cádiz, Tesis doctoral, Universitat Politècnica de Catalunya, 2004, consultada en https://www.tesisenred.net/handle/10803/277379\#page=1

Pateau, M., "Le complexe portuaire "Tanger Med”, une stratégie économique aux dépens d'une gestion durable de risques naturelles", Geographies, Bulletin de l'Association de Géographes Français, vol. 91, n³ 3, 2014, pp. 389 - 340.

Quesada López, Pedro Mabuel y M'Rabet, rabia, "Reflexiones jurídicas en torno al posible papel mediador de la Unión Europea en el contencioso de Gibraltar", Anuario Español de Derecho Internacional, vol. 33, 2017, pp. 337 - 368.

Romero Bartomeus, Luis, "Los actores que intervienen en la estrategia del Estrecho de Gibraltar", Cuadernos de Gibraltar / Gibraltar Reports, n² 2, 2016 2017, pp. $147-223$.

Santana, Anthony, "La conservación de los mamíferos en Gibraltar" en Revista de Estudios Campogibraltareños, Almoraima, v. 15, 1996, pp. 191 - 196.

Solandt, J. L., Stewart, B., Puritz, A., "Perspective: What does Brexit Mean for UK MPAs?", 18-04-2017, MPA News, https://mpanews.openchannels.org/news/mpa-news/perspective-what-doesbrexit-mean-uk-mpas

Shaw, E., "Gibraltar's Sea Grass Meadows" en Gibraltar Nature News, v. 43, Gibraltar, 1992, Shaw, E. "Dolphins in the Bay of Gibraltar" en Revista de Estudios Campogibraltareños Almoraima, v. 13, 1996, pp. 161 - 171.

Trinidad, Jamie, "The disputed waters around Gibraltar", The Bristish Yearbook of International Law, volumen 86, Issue 1, 2016, pp. 101 - 154.

Truver, S. C., The strait of Gibraltar and the Mediterranean, Sithoff \& Noordhoff, 1980.

Verdú Baeza, Jesús, "La controversia sobre las aguas de Gibraltar: el mito de la costa seca", Revista Española de Derecho Internacional, vol. 66, n 1, 2014, pp. $81-123$. 
- "Las aguas de Gibraltar, el tratado de Utrecht y el Derecho Internacional del Mar", Cuadernos de Gibraltar/Gibraltar Reports, n 1, 2015, pp. 97 - 132.

- "El medio ambiente como instrumento de cooperación transfronteriza: la Reserva de la Biosfera Intercontinental del Mediterráneo entre Andalucía y Marruecos", Anuario Español de Derecho Internacional, n² 28, 2012, pp. 397 416.

- "La doble declaración de Lugares de Interés Comunitario y la superposición de zonas marinas protegidas en aguas de Gibraltar, ¿una nueva controversia?, Revista Española de Derecho Internacional, 2009, 1, LXI, pp. 286 - 291.

Yturriaga Barberán, José Antonio, Straits Used for International navigation: A Spanish Perspective, Nijhoff Dorddrecht, 1991. 